\title{
Applied learning through international collaboration: Using research on domestic violence as a learning tool
}

Gámez Hernández, José Luis; Hidalgo López, Cristina; Surián Barrios, María de los Ángeles; Tushaus, David W.

Department of Criminal Justice, Legal Studies and Social Work, Missouri Western State University, United States.

\begin{abstract}
This article describes how applied learning may be achieved through a research project on an international scale. The research for this article was conducted by three Missouri Western State University (MWSU), U.S.A. exchange students from Spain in collaboration with the MWSU professor in charge of managing the project. This research involves an analysis of domestic violence. The main purpose of this study is to show what can be learned in the academic field through research from the perspective of advanced, undergraduate level students. This article will go over the processes the students followed to conduct good investigative work as well as the skills and abilities the researchers have mastered by working on this project. Such investigative work is comprised of three different approaches. The students were free to develop the research to explore the legal perspective, a sociological approach and the area of prevention of domestic violence. Each approach goes into the analysis of domestic violence to give a multidisciplinary understanding of this phenomenon. Finally, the paper offers examples of the results obtained from surveys conducted in Nepal by the MWSU professor and Nepal NGO, which were coded and interpreted by the three international students from Spain.
\end{abstract}

Keywords: Domestic violence; independent research; applied learning 


\section{Introduction.}

An important aspect of a student's academic path is to experience out-of-classroom learning. This helps to establish the necessary skills to develop a future professional career. Independent research is an available option for advanced level students at MWSU. Independent research can be an incredibly challenging and rewarding learning experience for students who want to try alternative academic methods and faculty who want to introduce students to do research in their discipline. The investigation that this team took part in is focused on domestic violence, more specifically domestic violence in Nepal, where the professor in charge collaborated with a Nepal NGO to carry out a survey of Mobile Legal Clinic clients. The students working on this project had the freedom to decide how to approach it, attending to certain data already available. This approach encourages independence and teamwork on the part of a small, student research team. Information and ideas are shared via various internet tools, from email to a shared cloud host for information. In this case an education based Google Drive, which provides more security and capacity than a traditional Google Drive.

The project mainly consisted of each student conducting a literature review to determine the most recent research on the domestic violence topic. Each student then developed an article from the literature review comparing the already existing literature related to the topic, and then analyzing the different aspects of this phenomenon in both western cultures and eastern cultures. While developing this paper, the team also had to evaluate the Mobile Legal Clinic survey conducted by the principal investigators in the United States and Nepal to make conclusions about the results from these surveys.

In this article, the goal is to share this multi-country experience primarily from the perspective of foreign exchange students from Spain so that others may replicate this process in their discipline and setting. These students worked on this investigative team lead by the U.S. Professor on the original research done in Nepal while the students were studying in the U.S. However, this project was finished after the students returned to Spain. Most of the work in the U.S. also could have been done through internet collaboration. All of the processes and steps will be presented so that others can see why and how they might do their own research project. Then, a brief presentation of the data obtained during the research will be explained, followed by some graphs and conclusions about the survey in Nepal. 


\section{Process.}

The research team consisted of three exchange students from the University of Sevilla (Spain), attending Missouri Western State University for one semester through a study abroad program. The students recognized the opportunities that studying in another country and educational system can provide and that their experiences would be beneficial for their knowledge in their academic field of Criminology.

At the beginning of the course, the students wanted to explore various course options. They were looking for more challenging opportunities. Professor Tushaus offered an opportunity to work on a research project on domestic violence, instead of sitting in on a traditional course in the classroom.

The students immersed themselves in the research, dedicated to learning more about this phenomenon of domestic violence. Some materials that were helpful for the research on this project, such as articles and previous student work, were provided by Professor Tushaus. This first step of acquiring more knowledge about the topic was essential for the students to learn about the process and substance of the research project, and the progression of the research work.

\subsection{Investigation approach.}

The students decided to focus on a comparative approach with regards to western and eastern societies. The reason for this was that as international students they wanted to contrast how this phenomenon develops within different cultural environments from the legal and social perspectives. The aim was to develop an overall theoretical framework to put the research into context, thus the team was able to critically analyze the information provided.

The theoretical references reviewed were to give the team a better understanding of the academic work already done on domestic violence. That way the students acquired the necessary skills to conduct research focused on domestic violence such as the analysis of the laws in force with regards to this issue; the review of the main sociological theories which are valid to explain why this phenomenon occurs and on which circumstances attending to two different models of culture; as well as certain propositions and strategies to prevent domestic violence.

\subsection{Surveys from Nepal}

Another important part of the project was to tabulate results from surveys taken in Nepal. It was the students' responsibility to interpret and code these surveys and incorporate the information found into a database. Having all of the research organized helped the students to compare articles and make conclusions later in the final section of the project. The 
students decided to write about different aspects of domestic violence in order to explore a cross-cultural aspect of domestic violence. By doing this, each of the students was able to look for separate articles related to the various aspects of domestic violence. The three points that the students chose to focus on were sociological approaches, prevention and action plans, and legal perspectives. They compared Eastern and Western countries using each of these points. Using these three points to divide the paper enabled the students to focus more on specific information related to domestic violence and more easily compare the differences between countries.

Gathering the data was crucial at the beginning since the students had to be able to manage technological research tools, in this case Microsoft Excel. The students had to get familiar with the program to select and interpret relevant details about every subject studied so that they could draw informed conclusions about the phenomenon as it occurred in Nepal.

The final part of this project involved analyzing the results of the surveys conducted in Nepal. The students compared their research with the results of the survey and contrasted the differences.

\section{Data.}

\subsection{Laws and measures}

The Convention on the Elimination of All Forms of Discrimination against Women (CEDAW) was pioneering in regards to the laws and measures developed towards domestic violence issues. In 1979, the United Nations General Assembly (UNGA) adopted the CEDAW, commonly referred to as the women's bill of rights. Article 18 of the Convention established that all members commit to submitting a report on any legislative, judicial, administrative, or any other measure they have taken to implement the Convention. This must be done within one year from the date of ratification or joining to the Convention. After the first 25 years of the Convention, the Committee has examined 401 reports presented by these members, accomplishing its function of vigilance established in the article (United Nations, 2007).

Laws in Eastern countries such as India or Nepal are focused on helping the victims by encouraging them to report their husbands or partners domestic violence. They also try to protect the economic independence of the victim and help them and their children survive after reporting their husbands. The economical dependence on their husbands is the main reason of these types of laws (Joshi, 2009).

On the other hand, laws regarding domestic violence in Europe or the United States work to reduce violence at home by punishing the offender. In the United States, there are laws that establish a protective order which criminalizes the offender's presence at home, controlling the relationships between the offender and the family members (Schawrz, 2011). Also, the 
Council of Europe Convention on prevention and combating violence against women and domestic violence was developed in 2011 , trying to encourage the Parties to implement measures to penalize domestic violence (Ratkovic, 2016).

\subsection{Sociological approach.}

In developing countries, the role of women in connection with domestic violence has not been investigated as fully, when compared to developed countries who have analyzed this connection more thoroughly. In fact, the results provided by the studies already conducted are quite diverse. For instance, in Bangladesh domestic violence has shown to be very dependent on the context which places women with high autonomy at a higher risk in conservative areas. Likewise, women from South India who take part in vocational and social activities present a higher likelihood of being victims of domestic violence (Lamichhane et al., 2011).

Social behavior patterns do not evolve as fast as other aspects such as industry or technology. The social role of women and their conduct within Indian society receives a direct influence from cultural customs or value systems which normally tend to enforce lower appreciation of females. This results in the failure to make effective and real the role that was given to women in the Constitution. The Constitution gives women the same rights as men and a role of equal importance and dignity (Mohapatra, 2015).

Roles and power of decision are governed by gender and age. The family structure in countries like India is to a considerable extent, influenced by patriarchal customs. Such setup encourages families to leave all the decision-making power to males (Sonawat, 2001).

Social and religious patterns in Nepal tend to enforce the submissive role of women in society and, therefore, to increase the possibility of the occurrence of violence (Lamichhane et al., 2011).

Families in Asian cultures are achieving quite positive changes regarding patriarchal structures and the perception of women (Sonawat, 2001), and the historical role of women is seen as one that must be respected. However, females are still having trouble improving the way they are perceived, as well as being able to effectively practice their rights due to gender discrimination. It is remarkable that governments can place effort and commitment in the prosecution of domestic violence crimes and their punishment, as well as their prevention by practically implementing females' rights and raising awareness among the population (Nagindrappa \& Radhika, 2013).

\subsection{Prevention and action plans}

Considering primary, secondary and tertiary prevention, domestic violence all over the world is a social problem which governments try to deal with. Primary prevention efforts 
are introducing new values in society and educating children, exploring awareness in domestic violence and the available resources for victims (Fernandez Alonso, 2003).

Secondary prevention is focused on at-risk individuals, reducing the factors that make the problem happen (Wolfe, \& Jaffe, 2003). Some risk factors are the same around different places, including early marriage, low socio-economic and education levels, or emotional and economic dependence on the husband among others (Center for Disease Control and Prevention, 2016).

However, other victimization characteristics are unique depending on the country. For instance, in the United States conditions of unemployment and belief in a strict gender role are frequent in domestic violence situations, according to the Center for Disease Control and Prevention (hereafter CDC) (2016). In European countries, such as Spain, establishing risk factors is important so that violence can be detected and stopped in time. These factors can be victim's low self-esteem, imbalance of power in the relationship and previous domestic violence in the family of origin, among others (Fernandez Alonso, 2003). On the other side, in India, there are some other differences on the risk factors that affect domestic violence (Mahaprato, Gupta, \& Gupta, 2012). Being between the ages of twenty-one and thirty-five, having a nonskilled job or a job that requires no higher education, or living in a low caste or low socioeconomic status all contribute to being more likely to be a victim of domestic violence.

One action plan directed toward domestic violence can be found in Europe, the Istanbul Convention. The main objectives are (Lousada Arocheda, 2014) promoting changes in behavior, eliminating stereotypes and role perceptions based on the inferiority of women, preventing any form of violence, encouraging society to contribute to the prevention of domestic violence, working to ensure that violence is not justified under any argument; and empowering women to help them gain autonomy. European countries are responsible for establishing measures to address these objectives.

In India, the NGOs contribute by providing shelter for victims and other resources such as education and counseling. The areas of action provided by the government involve criminalizing violence, institutionalizing responses, raising public awareness, and enriching the existing database. As well as India, the government of Nepal works on a prevention plan focused on achieving public awareness of gender-based violence, punishing perpetrators according to the law, and ensuring justice to victims (Government of Nepal, 2009). This study as discussed below surveyed people in Nepal who attended mobile legal clinics designed to provide public education and assess its value to those in attendance. 


\section{Survey results.}

The following information is concentrated on the data that has been extracted from the surveys. The format of this survey contemplates information about the type of problems experienced and what led the respondent to seek help from the Mobile Clinic in Nepal. The survey also shows the kind of help that can be obtained from the Mobile Legal Aid Clinic. The students used the surveys from the Mobile Clinics to learn more about the demographics of the respondents such as gender, age, incomes, educational level, and family size. This section proceeds to analyze and discuss the conclusions that were drawn from the surveys.

\subsection{Gender}

According to the data found in Nepal, the majority of the survey respondents are women, being $88.4 \%$ of the subjects, compared to $11.6 \%$ who are men. This coincides with the investigations and research previously collected, since the literature found was primarily focused on violence against women.

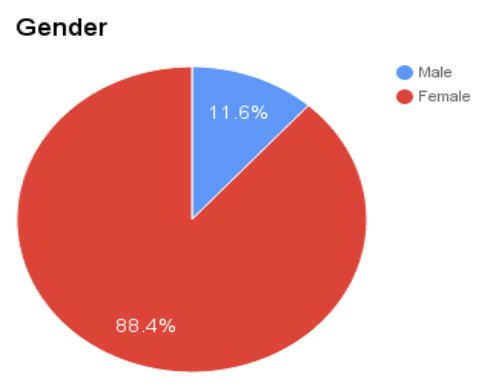

\subsection{Income and education}

According to the surveys collected in Nepal, the majority of the people receiving help from the Mobile Clinic had a monthly income lower than 20,000 Nepal Rupies. People with an income between Rs 20,000 and 10,001 consist of $37.9 \%$ of the subjects. Having an income between Rs 20,000 and 10,001 can be considered to be in a high economic status in Nepal. At the time this article was written 10,000 Nepal Rupees was worth less than $\$ 92$.

This may seem contradictory to what the research team has confirmed in the data since a notorious characteristic among the risk factors for domestic violence is low socio-economic status (CDC, 2016). 
The income may be related to the educational level of the respondent. Only $4 \%$ of the total respondents had a graduate level education. The rest of the subjects did not graduate, being the most common respondents with $5^{\text {th }}$ to $10^{\text {th }}$-grade level education. The results in this section are also in accordance with the data. Lower education is also a risk factor for domestic violence (CDC 2016).

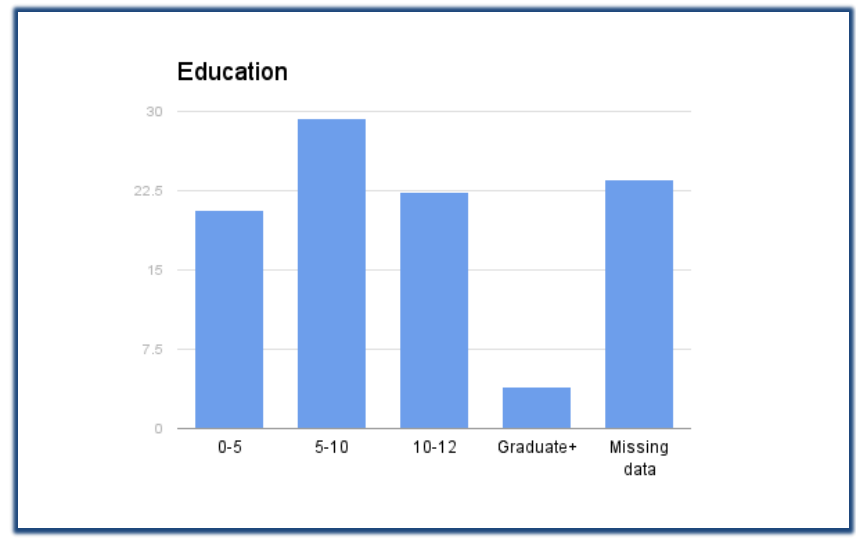

\subsection{Help received}

According to the statistics, the highest area of help received by victims of domestic violence is counseling with $78.9 \%$ of respondents participating. However, following the literature analyzed during the research, the resources provided to the victims by the laws in this country are focused on helping them in other aspects. The intent of this is to encourage the victims to report their partners and to be able to survive on their own, ensuring that their husbands (typically) do not leave them without any resources (Joshi, 2009).

\begin{tabular}{|c|c|}
\hline \multicolumn{2}{|l|}{ Help Received } \\
\hline Legal Problem. & $36.7 \%$ \\
\hline Written information about the problem & $24.4 \%$ \\
\hline Counsel on Problem & $78.9 \%$ \\
\hline Other & $1.1 \%$ \\
\hline Missing data & $5.7 \%$ \\
\hline
\end{tabular}




\subsection{Helpfulness of clinic}

This section seeks to determine if the information provided by the Mobile Clinic to the respondents was useful to them. An evaluation of the intervention shows a total of $63.2 \%$ found the Mobile Clinic helpful or very helpful. Most of these found it very helpful at $49.4 \%$. However, $10 \%$ of the respondents thought that it was just a little helpful while $0.6 \%$ answered not helpful at all. Unfortunately, $25.8 \%$ of the subjects did not answer this question.

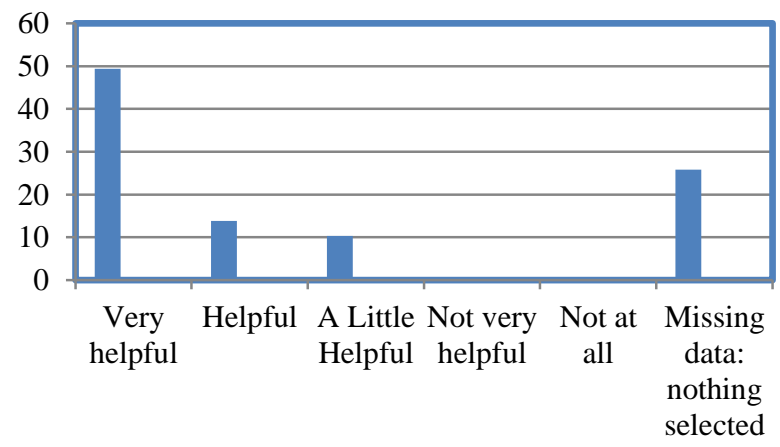

\section{Conclusions: educational achievements.}

An applied learning, international research project like this is replicable across disciplines and international boundaries, even at the undergraduate level. At its best, such a project accomplishes three main goals of faculty professional development. First and foremost, it is a scholarly activity. Faculty and the students who participate can contribute to the scholarly work in the research discipline.

Second, this is a teaching activity. The process serves as a teaching tool for conveying substantive and procedural knowledge. The upper level undergraduate student is exposed to the research process, the substantive area of the discipline being researched, how to communicate across international boundaries for the purpose of research and writing. This knowledge and the skills to apply it are transferable to subsequent research endeavors as well as in various business and other professional settings.

Third, a project like this can be a service activity if it is an applied learning project that provides a service to the community. In this case, the project initially helped to obtain funding for domestic violence Mobile Legal Aid Clinics in Nepal before this part of the 
research project began. This phase of the project helped to establish the benefits of the mobile clinics to the Nepal participants.

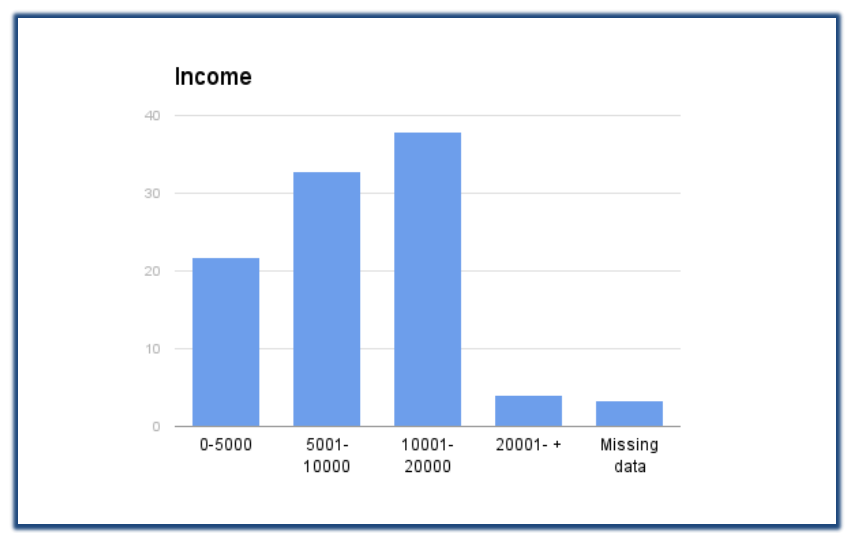

From the students' perspective, the project enabled the team to develop multiple skills that helped the students to conduct complex research and analysis on social phenomena such as domestic violence. Working on an investigation like this is an opportunity to put into practice the theoretical knowledge acquired while working towards a degree in Criminology.

Some of the benefits of taking part in independent research are developing teamwork abilities in a professional environment, understanding multiple objects of study from both qualitative and quantitative perspectives, and learning how to structure properly written work and references. This kind of research project gives professors an opportunity to use their research agenda to educate their students as noted above. Students learn first hand about the research process and a substantive area of the discipline. They also learn other important skills, from team building to international collaboration using internet communication and work strategies.

In terms of this substantive topic, the phenomenon of domestic violence has shown some patterns that differ and others that relate throughout several countries in the world. During this project, the researchers have explored this area of investigation from several perspectives. This way, the students can increase their writing, investigative and organizational capacities, as well as their creativity and, in this case, English skills. All this can be accomplished while making a substantive contribution to a specific topic in a discipline. 


\section{References}

Centers for disease control and prevention (2016). Intimate partner violence: Risk and Protective Factors. Retrieved from: http://www.cdc.gov/violenceprevention/intimatepartnerviolence/riskprotectivefact ors.html

Fernandez Alonso, M. (2003). Violencia Doméstica. SemFIC y Ministerio de Sanidad y Consumo. Madrid.

The government of Nepal (2009). National Plan of Action for "Year against Gender-Based Violence, 2010". Office of Prime Minister and Council of Ministers.

Joshi S. K. (2009). Violence against women in Nepal: Role of health care workers. Kathmandu University Medical Journal 7, 89-90. Retrieved from: http://akec.com.np/issue/26/89-90.pdf

Lamichane, P. (2011). Women's status and violence against young married women in rural Nepal. $\quad$ BMC Women's Health.

Lousada Arochena, J. F. (2014) El Convento del Consejo de Europa sobre prevención y lucha contra la violencia contra las mujeres y la violencia de género. Aequitas, $\mathrm{n}^{\mathrm{o}} 35.6-15$

Mahaprato, M., Gupta, N. R., \& Gupta, V. (2012). Risk factors in domestic violence in India. Indian Journal of community medicine. 153-157. Retrieved from: https://www.ncbi.nlm.nih.gov/pmc/articles/PMC3483507

Mohapatra, H. (2015), Status of women in Indian society. Journal of Research in Humanities and Social Science, 3 (6), 33-36. Retrieved from http://www.questjournals.org/jrhss/papers/vol3issue6/F363336.pdf

Nagindrappa, M., \& Radhika, M. K. (2013). Women exploitation in Indian modern society. International Journal of Scientific and Research Publications, 3(2), 1- 11.

Ratkovic, V. (2016). Violence against Women and Domestic Violence must be punished. Balkan Criminology News 2, 7. Retrieved from: http://balkan-criminology.eu/files/newsletter/balkancriminology-news_2016-02.pdf

Sonawat, R. (2001). Understanding families in India: A reflection of societal changes. Psicologia: Teoria e Pesquisa, 17(2), 177-186.

United Nations (2007). CEDAW 25 years (1982-2007): Committee on the Elimination of Discrimination against Women. Retrieved http://www.un.org/womenwatch/daw/cedaw/cedaw25years/content/spanish/introd uction.html

Visaria, L., Mitra, N., Poonacha, V., \& Pandey, D. (1999). Domestic violence in India. Washington, DC: International Center For Research on Women.

Wolfe, D. A., \& Jaffe, P. G. (2003). Prevention of the domestic violence and sexual assault. Applied Research Forum. VAWNET. Retrieved from: http://www.mmgconnect.com/projects/userfiles/file/dcestop_now/ar_prevention.pdf 